\title{
Red blood cell transfusion triggers and transfusion alternatives in elective orthopedic hip and knee replacement surgery - a review
}

This article was published in the following Dove Press journal:

International Journal of Clinical Transfusion Medicine

4 August 2015

Number of times this article has been viewed

\section{Cynthia So-Osman}

Department of Transfusion Medicine, Sanquin Blood Supply, Leiden, the Netherlands
Correspondence: Cynthia So-Osman Department of Transfusion Medicine, Sanquin Blood Supply, Plesmanlaan Ia, 2333 BZ Leiden, the Netherlands $\mathrm{Tel}+317$ I568 5136

Fax +3I7 I568 5I9I

Email c.so@sanquin.nl
Abstract: In elective hip and knee replacement surgery, the use of red blood cell transfusion alternatives has been widely accepted. However, nowadays, more evidence is accumulating that suggests some transfusion alternatives may no longer be cost effective. In this review, an evidence-based overview of the applied transfusion alternatives is provided, aiming for optimal and cost-effective patient blood management in elective hip and knee replacement surgery.

Keywords: patient blood management, erythropoietin, autologous blood, cell salvage

\section{Introduction}

Total hip and knee prosthesis surgery is performed worldwide approximately two million times annually and approximately 50,000 in the Netherlands. ${ }^{1}$ These surgeries may result in significant intra- and postoperative blood loss (800-1,500 mL), with a potential need for allogeneic red blood cell (RBC) transfusions to compensate for the resulting anemia. Although blood transfusions are relatively safe, transfusion reactions, such as fever, hemolysis, antibody formation, transfusion-associated cardiac overload (TACO), transfusion-related acute lung injury (TRALI), or transmission of infectious agents may occur. Furthermore, natural killer (NK) activity may be decreased in patients after an allogeneic RBC transfusion compared with no RBC transfusion or with autologous blood reinfusion. ${ }^{2}$ It has been postulated that due to immunomodulatory effects, allogeneic blood transfusions may result in an increased susceptibility to infections in the postoperative period. ${ }^{3-8}$ In the field of orthopedic surgery, as well as in other disciplines, there is an ongoing trend to aim for optimal patient blood management (PBM). PBM has been introduced in Transfusion Medicine as an evidence-based best practice that is based on three approaches (pillars): 1) optimizing the patient's own blood; 2) minimizing surgical blood loss and bleeding; and 3) harnessing and optimizing the patient-specific physiological reserve to compensate for anemia (including restrictive transfusion thresholds). ${ }^{9}$

This approach includes not only preoperative, intraoperative, and postoperative strategies for managing the patient, such as alternatives for RBC transfusions, but also surgical and anesthesiological strategies. A comprehensive overview of blood conservation strategies in major orthopedic surgery in the European setting was presented by Muñoz et al. ${ }^{10}$ In a more recent review, Ponnusamy et al discussed the potential complications of blood transfusions in orthopedic surgery patients and discussed the use of restrictive transfusion thresholds as a strategy to lower the need for RBC transfusions. It was suggested that RBC transfusions may place patients at greater risk for 
infections, including surgical site infections, which can be decreased by using a restrictive transfusion policy. ${ }^{11}$

In this review, an evidence-based overview is provided of the applied transfusion alternatives aiming for optimal and cost-effective PBM in elective hip and knee replacement surgery.

\section{Transfusion practice}

A large variation in transfusion policy among countries and even among hospitals within a country can still be seen as common practice. In the first Austrian benchmark study, Gombotz et al found a transfusion rate varying from $16 \%-85 \%$ for patients undergoing primary total hip replacement and a $12 \%-87 \%$ transfusion rate for patients undergoing primary total knee replacement surgery. ${ }^{12}$ In the second benchmark study, which was published recently, transfusion rates have decreased in total hip replacement (from $41 \%$ to $30 \%$ ) and total knee replacement (41\%-25\%), however, with still substantial between-center variability. ${ }^{13}$ These studies show that the implementation of guidelines in daily practice is difficult. This is relevant, not only for implementing transfusion thresholds but also, for the number of transfusions at each event to reach a particular target hemoglobin $(\mathrm{Hb})$ level. Barr et al investigated RBC transfusion practice in Northern Ireland in 2005 and still found a two-unit instead of single-unit transfusion practice in medical and surgery patients $(\mathrm{n}=1,474){ }^{14}$

\section{Blood transfusion threshold protocols}

Within the strategy of PBM, the use of a restrictive blood transfusion protocol can be regarded as an important bloodsaving and cost-saving strategy. In 1988, the National Institutes of Health (NIH) published consensus guidelines for RBC transfusions. ${ }^{15}$ Since then, several guidelines have been published, recommending that a range of $\mathrm{Hb}$ levels between 6 and $10 \mathrm{~g} / \mathrm{dL}$ can be used, depending on the presence of serious comorbidity. ${ }^{16-18}$ These clinical practice guidelines, however, have based their recommendations on data from published reports on series of patients for whom RBC transfusions were withheld (for instance Jehovah's witnesses) and observational studies, rather than on the results of clinical trials. Since June 2004, the 4-5-6 Flexinorm transfusion trigger $(\mathrm{Hb}$ values in $\mathrm{mmol} / \mathrm{L})$, based on the $\mathrm{NIH}$ guidelines, in the surgical setting has been recommended in the Dutch national consensus guideline for blood transfusion. This transfusion trigger policy is based on parameters as $\mathrm{Hb}$ level, age, and condition of the patient (American Society of Anesthesiologists [ASA] criteria). In 2012, an updated systematic review from Carson et $\mathrm{al}^{19}$ showed that restrictive transfusion strategies lowered the RBC transfusion risk by $39 \%$ (relative risk $[\mathrm{RR}]=0.61 ; 95 \%$ confidence interval [CI]: 0.52 to 0.72 ) and the mean transfusion rate by 1.19 units (95\% CI: 0.53 to 1.85 units). However, heterogeneity between the studies was high $\left(P<0.00001 ; I^{2}>93 \%\right)$ for these outcomes, and in some papers, the methodological quality was unclear. By using a restrictive transfusion strategy, postoperative complication rate was neither different from using a liberal transfusion strategy (ie, mortality and cardiovascular complications, such as myocardial infarction and stroke, pneumonia, and thromboembolic complications), nor was functional recovery, or hospital or intensive care length of stay. However, hospital mortality was significantly reduced in the groups with a restrictive transfusion strategy $(\mathrm{RR}=0.77 ; 95 \% \mathrm{CI}$ : 0.62 to 0.95$)$ but 30 day mortality was not $(\mathrm{RR}=0.85 ; 95 \% \mathrm{CI}: 0.70$ to 1.03). In this review, the results of the FOCUS trial was included, which randomized only patients with a positive cardiovascular history. ${ }^{19}$ The authors concluded that the existing evidence supported the use of restrictive transfusion triggers in the majority of patients, including patients with a cardiovascular history. ${ }^{20}$

A recent systematic review focused on the effect of transfusion thresholds on postoperative infection rate and concluded that restrictive transfusion thresholds lowered infection risk. ${ }^{21}$

The addition of single-unit transfusion policies have been investigated in several observational studies: A $25 \%$ reduction in $\mathrm{RBC}$ transfusions was found in hematological patients receiving intensive chemotherapy or stem cell transplantation. ${ }^{22}$ Observational studies in (orthopedic) surgery patients that implemented a single-unit policy next to a restrictive transfusion policy may lead to a larger reduction in RBC use. ${ }^{23-25}$

\section{Current alternatives for allogeneic RBC transfusions}

Many alternatives for allogeneic RBC transfusion are available. Not all interventions are widely applied. Next to efficacy, important factors that are of influence are costs, user friendliness, and safety. Based on randomized controlled studies, the efficacy of the different modalities will be discussed. The modalities of tourniquet use or acute hypervolemic hemodilution are regarded as being standard practice and are therefore not discussed here. The alternatives for allogeneic blood transfusion can be subdivided in 
two main groups: nonpharmacotherapeutic (group A) and pharmacotherapeutic interventions (group B) (Table 1).

\section{Current evidence on transfusion alternatives in elective hip and knee replacement surgery patients Nonpharmacotherapeutic interventions}

Preoperative alternatives:

Preoperative autologous donation (PAD)

Five trials reported on orthopedic surgery patients $(n=425)$ and showed a significant transfusion avoidance of $79 \%$. However, autologous orthopedic donors were more likely to have an increased overall transfusion rate with allogeneic and/or autologous blood (odds ratio [OR] $=1.78 ; 95 \% \mathrm{CI}$ : 0.61 to 5.20). ${ }^{26}$ The use of PAD is relatively expensive and complex and needs a fixed surgery date (the patient needs to visit the blood center several times to donate blood). In addition, the likelihood for mistakes by switching of blood products is high. ${ }^{27}$ The British guidelines only advise PAD in exceptional cases if the normal donor stock is insufficient, as in cases of rare blood group typing and/or antibodies against public antigens et cetera. ${ }^{28}$ The Dutch Blood Transfusion Guidelines (http://www.diliguide.nl/document/2903/bloedtransfusieupdate.html) advises a limited use of PAD, due to the complex logistics, the relative high costs, the lack of additional safety,

Table I Red blood cell transfusion alternatives (group A and group B)

Group A: nonpharmacotherapeutic interventions

I. Preoperative alternatives

- PAD $^{26,28}$

2. Perioperative alternatives

- $\mathrm{ANH}$, in which one or several units of whole blood is taken just before surgery and at the same time (= normovolemic), the lost blood volume is replaced by normal saline or colloids. The retained whole blood is then transfused back to the patient during or after surgery ${ }^{29,30}$

- Use of the cell saver, which collects autologous wound blood during (and sometimes after) surgery. The shed blood is washed, concentrated, and then reinfused ${ }^{31,33}$

3. Postoperative alternatives

- Devices that collect and reinfuse autologous wound blood after surgery (unwashed, filtered by several types of devices) 31,33

Group B: pharmacotherapeutic interventions

I. To increase preoperative hemoglobin level

- The preoperative use of Epo ${ }^{34-36,40}$ and the preoperative use of (intravenous) iron ${ }^{51-54}$

2. To reduce perioperative blood loss

- The perioperative use of antifibrinolytics, eg, aprotinin, ${ }^{55}$ tranexamic acid, ${ }^{60}$ and fibrin glue ${ }^{69,70}$

Abbreviations: $\mathrm{ANH}$, acute normovolemic hemodilution; Epo, erythropoietin; PAD, preoperative autologous donation. and the waste of plasma products (side product of PAD), and also recommends its use only for specific indications, such as lack of compatible blood units in cases of rare blood groups, antibodies to public or multiple RBC antigens, and the occurrence of former hemolytic transfusion reactions with unknown cause.

\section{Perioperative alternatives}

Acute normovolemic hemodilution (ANH)

Two systematic reviews reported on the use of ANH in six and 13 orthopedic trials, respectively. ${ }^{29,30}$ Both did not report a significant benefit of ANH for transfusion avoidance. Compared with another blood-sparing modality (PAD or tranexamic acid [TXA]), ANH was less effective in orthopedic patients..$^{30}$ As a transfusion alternative, $\mathrm{ANH}$ is therefore not recommended in knee and hip surgery.

\section{Peri- and postoperative alternatives}

Autologous reinfusion (cell saver and postoperative reinfusion systems)

In a Cochrane review ${ }^{31}$ evaluating all randomized studies up to 1 June 2009 in which the effect on RBC use of washed shed blood (by means of cell saver) or unwashed shed blood by means of postoperative reinfusion systems, 36 studies reported on orthopedic surgery. The authors concluded a significant transfusion avoidance of $54 \%$ and a significant mean RBC-sparing of $0.82 \mathrm{RBC}$ units/patient as well. The outcomes were similar using washed or unwashed blood. The authors, however, concluded that the methodological quality was poor and that the findings could have been influenced by bias. There was a lack of concealment, meaning that allocation of the randomization was not centralized but often, on location, by drawing an opaque envelope. This method can be susceptible to bias because it cannot be confirmed that the envelopes are drawn in the proper order. ${ }^{32}$ In an updated systematic review (van Bodegom-Vos et $\mathrm{al}^{33}$ ) that included all randomized controlled studies until January 2013, a time effect was found, including that studies published from 2010 onward resulted in a loss of blood-sparing effect of autologous reinfusion in both knee and hip replacement surgeries. This could be explained by the use of restrictive transfusion thresholds in the later studies.

\section{Pharmacotherapeutic interventions}

Interventions to increase the preoperative $\mathrm{Hb}$ level Erythropoietin (Epo)

Many randomized studies have been published in which the effect of Epo on RBC use has been investigated. Older 
studies report on the effect of Epo on the efficacy of PAD. In a meta-analysis by Laupacis and Fergusson, ${ }^{34}$ in orthopedic surgery, Epo resulted in a significant transfusion avoidance of $58 \%$ with, or $64 \%$ without, combination with PAD (eleven trials with PAD and three trials without PAD), but Epo did not significantly reduce the mean $\mathrm{RBC}$ use. The main reason for this finding was the low mean number of transfusions in the control group ( $0.46 \mathrm{RBC}$ units/patient), and a subsequent nonsignificant decrease of $0.14 \mathrm{RBC}$ units/patient after use of Epo. This finding was confirmed by a large European randomized study ( $\mathrm{n}=695$ ) (the EEST study) by Weber et al, ${ }^{35}$ who found a proportion of $12 \%$ transfused patients in the Epo group, which was significantly lower than the $46 \%$ transfused patients of the control group $(P<0.001)$, and also a nonsignificant difference in mean (standard deviation) $\mathrm{RBC}$ use (1.25 [0.51] RBC units/patient versus 1.42 [0.70] RBC units/ patient, respectively $[P=0.14])$. An updated meta-analysis by Alsaleh et al, ${ }^{36}$ performed on elective orthopedic surgery, reported the results of 26 trials including 3,560 participants and showed that the use of preoperative Epo reduced RBC transfusions in patients undergoing hip or knee surgery ( $\mathrm{RR}=0.48 ; 95 \% \mathrm{CI}: 0.38$ to $0.60 ; P<0.00001)$. There was no difference in the risk of developing thromboembolism between Epo and control groups (risk difference =0; 95\% CI: $-1 \%$ to $2 \% ; P=0.95)$. The authors concluded that Epo offers an alternative blood conservation method to avoid allogeneic $\mathrm{RBC}$ transfusions in patients undergoing hip or knee surgery. However, more evidence has been accumulating that shows Epo exceeds the costs of an allogeneic blood transfusion and therefore turns out to be not cost effective. ${ }^{37-40}$

\section{Intravenous (IV) iron}

Anemia increases with age, with an overall prevalence of $11 \%$ in males and of $10 \%$ in females older than 65 years, if defined according to the World Health Organization (WHO) criteria. ${ }^{41-44}$ One-third can be explained by nutritional causes (of which half are due to iron deficiency), one-third by anemia of chronic disease, and unexplained anemia in the remaining one-third of patients. These latter two categories of patients are characterized by low Epo levels and low levels of proinflammatory cytokines. ${ }^{45,46}$

If anemia is due to nutritional causes, correction might be easily performed by supplementing the deficient components. However, if anemia is due to anemia of chronic disease or unexplained anemia, it may be necessary to find the underlying disease that causes the anemia (eg, kidney failure or malignancy). If a patient is then still eligible for elective surgery, preoperative measures to increase the $\mathrm{Hb}$ level can be considered.
Since the preoperative $\mathrm{Hb}$ level was consistently reported as an independent significant risk factor for a $\mathrm{RBC}$ transfusion, it was included in the workup for optimizing perioperative PBM. ${ }^{47,48}$ A PBM protocol was developed by a Network for Advancement of Tranfusion Alternatives (NATA) working party aiming for preoperative nonanemic levels in the elective orthopedic surgery population. In this specific population, $14,1 \%$ suffer from preoperative anemia. ${ }^{49}$ Due to the elective character, the optimal preoperative treatment can be explored. Use of Epo (combined with oral iron) to increase $\mathrm{Hb}$ to normal levels is very costly. A less costly alternative may be the use of IV iron, since IV iron therapy may increase $\mathrm{Hb}$ values, not only in iron-deficient patients but also, in patients with anemia of chronic disease, bypassing the blocking effect of hepcidin that makes iron unavailable for incorporation in RBCs. ${ }^{50}$ Whether patients with unexplained anemia benefit from either IV iron or Epo therapy, or are refractory to both treatments, is unknown and must be further evaluated.

The efficacy and safety of IV iron compared with oral iron or to placebo was studied in several randomized trials and was reported in a systematic review. ${ }^{51}$ In that review, IV iron significantly increased $\mathrm{Hb}$ levels compared with placebo and oral iron. Furthermore, the use of IV iron was safe.

In orthopedic surgery, no randomized trials have been published that primarily evaluated the use of IV iron as a transfusion alternative and compared its effect with other blood management modalities. However, in hip fracture surgery, a randomized pilot study showed that transfusion requirements in patients with intracapsular fracture or baseline $\mathrm{Hb}$ level of $12 \mathrm{~g} / \mathrm{dL}$ or more appear to be reduced by IV iron therapy, without any difference in morbidity, mortality, or length of hospital stay. ${ }^{52}$ Other randomized studies are currently underway. ${ }^{53,54}$

\section{Interventions to reduce perioperative blood loss Antifibrinolytics}

Since trials on antifibrinolytics comprised mostly cardiac surgery patients, who differ from orthopedic surgery patients, outcome for RBC use may also be quite different between these two study populations. The results of trials of the orthopedic surgery population are discussed here.

\section{Interventional drug versus control group Aprotinin}

In a meta-analysis involving 18 randomized controlled trials (1,276 major orthopedic surgery patients), Huang et al found that aprotinin led to a significant reduction in transfusion requirements ( $\mathrm{RR}=0.59 ; 95 \% \mathrm{CI}$ : 0.51 to 0.69 ). The use of aprotinin significantly reduced total blood loss by a mean of 
$498.88 \mathrm{~mL}$ (95\% CI: -735.03 to -262.72$)$ and the number of blood transfusions per patient by 0.93 units $(95 \% \mathrm{CI}:-1.36$ to -0.51 ), without an increase in the risk of deep vein thrombosis (DVT) $(\mathrm{RR}=0.58$; 95\% CI: 0.38 to 1.08$) .{ }^{55}$

After a study in cardiac surgery patients (the BART study) showed that aprotinin was significantly associated with increased mortality compared with TXA and epsilon amino caproic acid (EACA), the use was prohibited. ${ }^{56}$ Nowadays, more and more data is accumulating in favor of aprotinin. ${ }^{57,58}$ Following its withdrawal in 2007, the regulators now license aprotinin for myocardial revascularisation only, which is at relatively low risk for bleeding. ${ }^{59}$

\section{TXA}

A meta-analysis on the use of TXA compared with controls reported a total of 46 randomized controlled trials involving 2,925 patients. The use of TXA significantly reduced total blood loss by a mean of $408.33 \mathrm{~mL}(95 \% \mathrm{CI}:-505.69$ to -310.77$)$ and the number of blood transfusions per patient by 0.78 units ( $95 \% \mathrm{CI}:-0.19$ to -0.37$)$. TXA led to a significant reduction in transfusion requirements $(\mathrm{RR}=0.51$; 95\% CI: 0.46 to 0.56 ) and no increase in the risk of DVT ( $\mathrm{RR}=1.11 ; 95 \% \mathrm{CI}: 0.69$ to 1.79$)$. The authors concluded that TXA significantly reduced blood loss and blood transfusion requirements in patients undergoing orthopedic surgery and did not appear to increase the risk of thromboembolic events. ${ }^{60}$ However, others discussed that its safety remains uncertain and that this needs to be the subject of future research. ${ }^{61,62}$

\section{EACA}

A meta-analysis reported 16 trials of EACA compared with controls, four trials involved orthopedic surgery $(n=304$ patients) in which the use of EACA did not reduce the need for allogeneic RBC transfusions. Two trials reported a marginally effective reduction in total blood loss of 300 $\mathrm{mL}$ (mean difference 95\% CI: 77 to 523). Mortality risk, risk of myocardial infarction, and thrombotic events were not increased. ${ }^{63}$

\section{Comparison among antifibrinolytics Aprotinin versus TXA}

Of 21 trials on aprotinin versus TXA that reported data on the number of patients exposed to allogeneic RBC transfusions, only one study ${ }^{64}$ was performed in orthopedic surgery patients (knee replacement surgery $[n=36]$ ). The study size consisted of three groups of 12 patients (controls versus TXA versus aprotinin, respectively) and showed no difference in the transfusion rate between all three groups.
No adverse outcomes were reported other than DVTs ( $n=2$ in the TXA group, $n=1$ in aprotinin group, and $n=0$ in control group). ${ }^{63}$

\section{Aprotinin versus EACA}

Of 12 reported trials, three (reported by Amar et al ${ }^{65}$ on spinal surgery [ $n=69]$, by Ray et $\mathrm{al}^{66}$ on hip surgery [ $\left.\mathrm{n}=45\right]$, and by Urban et $\mathrm{l}^{67}$ on spinal surgery $[\mathrm{n}=60]$ ) investigated orthopedic surgery patients: no significant transfusion avoidance was found with aprotinin compared with $\mathrm{EACA}(\mathrm{RR}=0.82 ; 95 \% \mathrm{CI}: 0.48$ to 1.40$).{ }^{65-67}$ The RR, however, was comparable with the risk in cardiac surgery patients, in which a significant transfusion avoidance with aprotinin was found ( $\mathrm{RR}=0.82 ; 95 \% \mathrm{CI}: 0.76$ to 0.89 ). Ray et al performed a study on 45 total hip arthroplasty patients $^{66}$ and did not find a difference in blood loss between aprotinin and EACA (for each, there were 15 patients per group) or in mean $\mathrm{RBC}$ reduction or transfusion avoidance.

Pooled data on adverse events (myocardial infarction and thrombotic events) showed no difference between the study and control groups. In the single-hip surgery trial of Ray et al, ${ }^{66}$ no thrombotic events, such as DVT or pulmonary embolism were found. Six cardiac adverse events were reported postoperatively in the intervention groups: two non-ST elevation myocardial infarction, two atrial fibrillation, and two patients with both myocardial infarction and atrial fibrillation; however, this did not reach statistical significance compared with the control group in these 45 patients $(P=0.08) .{ }^{63}$

\section{TXA versus EACA}

Of eight reported trials $(n=2,003)$, only one orthopedic study (knee replacement surgery $[\mathrm{n}=127])$ compared TXA $(\mathrm{n}=35)$ with EACA ( $n=32)$ and placebo $(n=60)$, and found no difference in blood loss between TXA and EACA or in transfusion avoidance, mean $\mathrm{RBC}$ reduction, or adverse events. ${ }^{68}$

\section{Fibrin glue}

Fibrin glue generally consists of two major components, fibrinogen and thrombin, which when applied to wound surfaces, helps to stop the bleeding. This sealant can be prepared from allogeneic or from autologous blood. The glue is generally sprayed directly onto wound surfaces during surgery in order to reduce blood loss and therefore, may avoid blood transfusions. Carless et al concluded, in a Cochrane review, that especially in orthopedic surgery, where blood loss is often substantial, fibrin sealants appear to demonstrate their greatest beneficial effects by significantly reducing blood loss and transfusion by $32 \%(\mathrm{RR}=0.68 ; 95 \% \mathrm{CI}$ : 0.51 to 0.89$)$, but large randomized controlled trials were lacking. ${ }^{69}$ An updated 
meta-analysis by Wang et al investigated the efficacy and safety of fibrin sealant in terms of blood loss, Hb level, range of motion, length of hospital stay, and complications. The authors concluded that the use of fibrin sealant was effective and safe as a hemostatic therapy for patients with total knee arthroplasty. Despite the limitations in this meta-analysis (few studies, low numbers, and heterogeneity between studies), fibrin sealant treatment may be considered for the total knee replacement surgery patient. $^{70}$

\section{Discussion and concluding remarks}

Since the frequency of knee and hip replacement surgery is exponentially growing, expecting a twofold increase from 50,000 to more than 100,000 arthroplasties in 2030 in the Netherlands, ${ }^{1}$ optimizing perioperative blood management is, not only highly relevant with respect to patient risks and benefits but also, important in terms of cost effectiveness. Although RBC transfusion alternatives are widely available, nowadays, more and more evidence is accumulating that shows some transfusion alternatives may no longer be cost effective for the general elective hip or knee replacement surgery patient. In the perspective of PBM, the first and most cost-effective blood-sparing modality will be the implementation of a restrictive transfusion threshold, including a single-unit transfusion policy. Compared with controls, the antifibrinolytic agents aprotinin and TXA resulted in significant transfusion avoidance. Due to its low costs and its safe use, TXA can be used as an acceptable modality, in addition to a restrictive transfusion policy, to lower blood use. In systematic reviews, the use of PAD, ANH, and cell salvage have lost their value as transfusion alternatives. The role of fibrin glue has not yet been established. Epo remains as a blood-sparing alternative, however, at unacceptably high costs. Nowadays, the PBM focus has shifted to the preoperative anemic patient, who can be regarded as a patient at risk for a RBC transfusion, for which IV iron may be an acceptable transfusion alternative. However, more studies are needed to make definite conclusions on this modality. Overall, for all potential transfusion alternatives, the costs and safety associated with its use should always be weighed against the benefits.

\section{Disclosure}

The author reports no conflicts of interest in this work.

\section{References}

1. Otten R, van Roermund PM, Picavet HS. [Trends in the number of knee and hip arthroplasties: considerably more knee and hip prostheses due to osteoarthritis in 2030]. Ned Tijdschr Geneeskd. 2010;154:A1534. Dutch.
2. Gharehbaghian A, Haque KM, Truman C, et al. Effect of autologous salvaged blood on postoperative natural killer cell precursor frequency. Lancet. 2004;363(9414):1025-1030.

3. Duffy G, Neal KR. Differences in post-operative infection rates between patients receiving autologous and allogeneic blood transfusion: a metaanalysis of published randomized and nonrandomized studies. Transfus Med. 1996;6(4):325-328.

4. Fernandez MC, Gottlieb M, Menitove JE. Blood transfusion and postoperative infection in orthopedic patients. Transfusion. 1992;32(4): 318-322.

5. Jensen LS, Andersen AJ, Christiansen PM, et al. Postoperative infection and natural killer cell function following blood transfusion in patients undergoing elective colorectal surgery. Br J Surg. 1992;79(6): 513-516.

6. Murphy P, Heal JM, Blumberg N. Infection or suspected infection after hip replacement surgery with autologous or homologous blood transfusions. Transfusion. 1991;31(3):212-217.

7. Vignali A, Braga M, Gianotti L, et al. A single unit of transfused allogeneic blood increases postoperative infections. Vox Sang. 1996;71(3): $170-175$.

8. Triulzi DJ, Vanek K, Ryan DH, Blumberg N. A clinical and immunologic study of blood transfusion and postoperative bacterial infection in spinal surgery. Transfusion. 1992;32(6):517-524.

9. Isbister JP. The three-pillar matrix of patient blood management - an overview. Best Pract Res Clin Anaesthesiol. 2013;27(1):69-84.

10. Muñoz M, García-Erce JA, Villar I, Thomas D. Blood conservation strategies in major orthopaedic surgery: efficacy, safety and European regulations. Vox Sang. 2009;96(1):1-13.

11. Ponnusamy KE, Kim TJ, Khanuja HS. Perioperative blood transfusions in orthopaedic surgery. J Bone Joint Surg Am. 2014;96(21):1836-1844.

12. Gombotz H, Rehak PH, Shander A, Hofmann A. Blood use in elective surgery: the Austrian benchmark study. Transfusion. 2007;47(8): 1468-1480.

13. Gombotz H, Rehak PH, Shander A, Hofmann A. The second Austrian benchmark study for blood use in elective surgery: results and practice change. Transfusion. 2014;54(10 Pt 2):2646-2657.

14. Barr PJ, Donnelly M, Morris K, Parker M, Cardwell C, Bailie KE. The epidemiology of red cell transfusion. Vox Sang. 2010;99(3):239-250.

15. Consensus conference. Perioperative red blood cell transfusion. JAMA. 1988;260(18):2700-2703.

16. Royal College of Physicians of Edinburgh. Consensus statement on red cell transfusion. Royal College of Physicians of Edinburgh. Transfus Med. 1994;4(3):177-178.

17. American Society of Anesthesiologists Task Force on Blood Component Therapy. Practice guidelines for blood component therapy: A report by the American Society of Anesthesiologists Task Force on Blood Component Therapy. Anesthesiology. 1996;84(3):732-747.

18. American Society of Anesthesiologists Task Force on Perioperative Blood Transfusion and Adjuvant Therapies. Practice guidelines for perioperative blood transfusion and adjuvant therapies: an updated report by the American Society of Anesthesiologists Task Force on Perioperative Blood Transfusion and Adjuvant Therapies. Anesthesiology. 2006;105(1):198-208.

19. Carson JL, Terrin ML, Noveck H, et al; FOCUS Investigators. Liberal or restrictive transfusion in high-risk patients after hip surgery. $N$ Engl J Med. 2011;365(26):2453-2462.

20. Carson JL, Carless PA, Hébert PC. Transfusion thresholds and other strategies for guiding allogeneic red blood cell transfusion. Cochrane Database Syst Rev. 2012;4:CD002042.

21. Holst LB, Haase N, Wetterslev J, et al; TRISS Trial Group; Scandinavian Critical Care Trials Group. Lower versus higher hemoglobin threshold for transfusion in septic shock. N Engl J Med. 2014;371(15):1381-1391.

22. Berger MD, Gerber B, Arn K, Senn O, Schanz U, Stussi G. Significant reduction of red blood cell transfusion requirements by changing from a double-unit to a single-unit transfusion policy in patients receiving intensive chemotherapy or stem cell transplantation. Haematologica. 2012;97(1):116-122. 
23. Leahy MF, Roberts H, Mukhtar SA, et al; Western Australian Patient Blood Management Program. A pragmatic approach to embedding patient blood management in a tertiary hospital. Transfusion. 2014;54(4):1133-1145.

24. Ma M, Eckert K, Ralley F, Chin-Yee I. A retrospective study evaluating single-unit red blood cell transfusions in reducing allogeneic blood exposure. Transfus Med. 2005;15(4):307-312.

25. Naylor JM, Adie S, Fransen M, Dietsch S, Harris I. Endorsing singleunit transfusion combined with a restrictive haemoglobin transfusion threshold after knee arthroplasty. Qual Saf Health Care. 2010;19(3): 239-243.

26. Henry DA, Carless PA, Moxey AJ, et al. Pre-operative autologous donation for minimising perioperative allogeneic blood transfusion. Cochrane Database Syst Rev. 2010;4:CD003602.

27. Wiersum-Osselton JC, Schipperus MR. [Transfusion reactions in patients: haemovigilance reports to the Dutch National Haemovigilance Office in 2003]. Ned Tijdschr Geneeskd. 2005;149(47):2622-2627. Dutch.

28. Boulton FE, James V; British Committee for Standards in Haematology, Transfusion Task Force. Guidelines for policies on alternatives to allogeneic blood transfusion. 1. Predeposit autologous blood donation and transfusion. Transfus Med. 2007;17(5):354-365.

29. Carless P, Moxey A, O’Connell D, Henry D. Autologous transfusion techniques: a systematic review of their efficacy. Transfus Med. 2004; 14(2):123-144.

30. Segal JB, Blasco-Colmenares E, Norris EJ, Guallar E. Preoperative acute normovolemic hemodilution: a meta-analysis. Transfusion. 2004;44(5):632-644.

31. Carless PA, Henry DA, Moxey AJ, O'connell DL, Brown T, Fergusson DA Cell salvage for minimising perioperative allogeneic blood transfusion. Cochrane Database Syst Rev. 2006;4:CD001888.

32. Torgerson DJ, Roberts C. Understanding controlled trials. Randomisation methods: concealment. BMJ. 1999;319(7206):375-376.

33. van Bodegom-Vos L, Voorn VM, So-Osman C, Vliet Vlieland TP, Dahan A, Koopman-van Gemert AW, Vehmeijer SB, Nelissen RG, Marang-van de Mheen PJ. Cell Salvage in Hip and Knee Arthroplasty: A Meta-Analysis of Randomized Controlled Trials. J Bone Joint Surg Am. 2015; Jun 17;97(12):1012-21. doi: 10.2106/JBJS.N.00315. PMID: 26085536.

34. Laupacis A, Fergusson D. Erythropoietin to minimize perioperative blood transfusion: a systematic review of randomized trials. The International Study of Peri-operative Transfusion (ISPOT) Investigators. Transfus Med. 1998;8(4):309-317.

35. Weber EW, Slappendel R, Hémon Y, et al. Effects of epoetin alfa on blood transfusions and postoperative recovery in orthopaedic surgery: the European Epoetin Alfa Surgery Trial (EEST). Eur J Anaesthesiol. 2005;22(4):249-257.

36. Alsaleh K, Alotaibi GS, Almodaimegh HS, Aleem AA, Kouroukis CT. The use of preoperative erythropoiesis-stimulating agents (ESAs) in patients who underwent knee or hip arthroplasty: a meta-analysis of randomized clinical trials. J Arthroplasty. 2013 Oct;28(9):1463-72. doi: 10.1016/j.arth.2013.01.024. Epub 2013 Mar 23.

37. Coyle D, Lee KM, Fergusson DA, Laupacis A. Economic analysis of erythropoietin use in orthopaedic surgery. Transfus Med. 1999;9(1) 21-30.

38. Fergusson DA, Hébert P. The health(y) cost of erythropoietin in orthopedic surgery. Can J Anaesth. 2005;52(4):347-351.

39. Bedair H, Yang J, Dwyer MK, McCarthy JC. Preoperative erythropoietin alpha reduces postoperative transfusions in THA and TKA but may not be cost-effective. Clin Orthop Relat Res. 2015;473(2):590-596.

40. So-Osman C, Nelissen RG, Koopman-van Gemert AW, et al. Patient blood management in elective total hip- and knee-replacement surgery (Part 1): a randomized controlled trial on erythropoietin and blood salvage as transfusion alternatives using a restrictive transfusion policy in erythropoietin-eligible patients. Anesthesiology. 2014;120(4):839-851.

41. Nutritional anaemias. Report of a WHO scientific group. World Health Organ Tech Rep Ser. 1968;405:5-37.
42. Guralnik JM, Eisenstaedt RS, Ferrucci L, Klein HG, Woodman RC Prevalence of anemia in persons 65 years and older in the United States: evidence for a high rate of unexplained anemia. Blood. 2004;104(8): 2263-2268.

43. Inelmen EM, D’Alessio M, Gatto MR, et al. Descriptive analysis of the prevalence of anemia in a randomly selected sample of elderly people living at home: some results of an Italian multicentric study. Aging (Milano). 1994;6(2):81-89.

44. Salive ME, Cornoni-Huntley J, Guralnik JM, et al. Anemia and hemoglobin levels in older persons: relationship with age, gender, and health status. J Am Geriatr Soc. 1992;40(5):489-496.

45. Ferrucci L, Guralnik JM, Bandinelli S, et al. Unexplained anaemia in older persons is characterised by low erythropoietin and low levels of pro-inflammatory markers. Br J Haematol. 2007;136(6):849-855.

46. Merchant AA, Roy CN. Not so benign haematology: anaemia of the elderly. Br J Haematol. 2012;156(2):173-185.

47. Goodnough LT, Maniatis A, Earnshaw P, et al. Detection, evaluation, and management of preoperative anaemia in the elective orthopaedic surgical patient: NATA guidelines. Br J Anaesth. 2011;106(1):13-22.

48. Spahn DR. Anemia and patient blood management in hip and knee surgery: a systematic review of the literature. Anesthesiology. 2010; 113(2):482-495

49. Lasocki S, Krauspe R, von Heymann C, Mezzacasa A, Chainey S, Spahn DR. PREPARE: the prevalence of perioperative anaemia and need for patient blood management in elective orthopaedic surgery: a multicentre, observational study. Eur J Anaesthesiol. 2015;32(3):160-167.

50. Cullis JO. Diagnosis and management of anaemia of chronic disease: current status. Br J Haematol. 2011;154(3):289-300.

51. Moore RA, Gaskell H, Rose P, Allan J. Meta-analysis of efficacy and safety of intravenous ferric carboxymaltose (Ferinject) from clinical trial reports and published trial data. BMC Blood Disord. 2011;11:4.

52. Serrano-Trenas JA, Ugalde PF, Cabello LM, Chofles LC, Lázaro PS, Benítez PC. Role of perioperative intravenous iron therapy in elderly hip fracture patients: a single-center randomized controlled trial. Transfusion. 2011;51(1):97-104.

53. Rowlands M, Forward DP, Sahota O, Moppett IK. The effect of intravenous iron on postoperative transfusion requirements in hip fracture patients: study protocol for a randomized controlled trial. Trials. $2013 ; 14: 288$.

54. Bernabeu-Wittel M, Aparicio R, Romero M, et al; PAHFRAC-01 investigators. Ferric carboxymaltose with or without erythropoietin for the prevention of red-cell transfusions in the perioperative period of osteoporotic hip fractures: a randomized controlled trial. The PAHFRAC-01 project. BMC Musculoskelet Disord. 2012;13:27.

55. Huang F, Zhao Q, Guo C, et al. Use of aprotinin to reduce blood loss and transfusion in major orthopedic surgery: a meta-analysis. Transfus Apher Sci. 2014;51(2):152-161.

56. Fergusson DA, Hébert PC, Mazer CD, et al; BART Investigators. A comparison of aprotinin and lysine analogues in high-risk cardiac surgery. $N$ Engl J Med. 2008;358(22):2319-2331.

57. Beckerman Z, Shopen Y, Alon H, et al. Coronary artery bypass grafting after aprotinin: are we doing better? J Thorac Cardiovasc Surg. 2013; 145(1):243-248.

58. Walkden GJ, Verheyden V, Goudie R, Murphy GJ. Increased perioperative mortality following aprotinin withdrawal: a real-world analysis of blood management strategies in adult cardiac surgery. Intensive Care Med. 2013;39(10):1808-1817.

59. Royston D. The current place of aprotinin in the management of bleeding. Anaesthesia. 2015;70 Suppl 1:S46-S49, e17.

60. Huang F, Wu D, Ma G, Yin Z, Wang Q. The use of tranexamic acid to reduce blood loss and transfusion in major orthopedic surgery: a meta-analysis. J Surg Res. 2014;186(1):318-327.

61. Hunt BJ. The current place of tranexamic acid in the management of bleeding. Anaesthesia. 2015;70 Suppl 1:S50-S53, e18.

62. Ker K, Edwards P, Perel P, Shakur H, Roberts I. Effect of tranexamic acid on surgical bleeding: systematic review and cumulative meta-analysis. BMJ. 2012;344:e3054 
63. Henry DA, Carless PA, Moxey AJ, et al. Anti-fibrinolytic use for minimising perioperative allogeneic blood transfusion. Cochrane Database Syst Rev. 2011;1:CD001886.

64. Engel JM, Hohaus T, Ruwoldt R, Menges T, Jürgensen I, Hempelmann G. Regional hemostatic status and blood requirements after total knee arthroplasty with and without tranexamic acid or aprotinin. Anesth Analg. 2001;92(3):775-780.

65. Amar D, Grant FM, Zhang H, Boland PJ, Leung DH, Healey JA. Antifibrinolytic therapy and perioperative blood loss in cancer patients undergoing major orthopedic surgery. Anesthesiology. 2003;98(2): $337-342$.

66. Ray M, Hatcher S, Whitehouse SL, Crawford S, Crawford R. Aprotinin and epsilon aminocaproic acid are effective in reducing blood loss after primary total hip arthroplasty - a prospective randomized double-blind placebo-controlled study. J Thromb Haemost. 2005;3(7):1421-1427.
67. Urban MK, Beckman J, Gordon M, Urquhart B, Boachie-Adjei O. The efficacy of antifibrinolytics in the reduction of blood loss during complex adult reconstructive spine surgery. Spine (Phila Pa 1976). 2001;26(10):1152-1156.

68. Camarasa MA, Ollé G, Serra-Prat M, et al. Efficacy of aminocaproic, tranexamic acids in the control of bleeding during total knee replacement: a randomized clinical trial. Br J Anaesth. 2006;96(5):576-582.

69. Carless PA, Henry DA, Anthony DM. Fibrin sealant use for minimising peri-operative allogeneic blood transfusion. Cochrane Database Syst Rev. 2003;2:CD004171.

70. Wang H, Shan L, Zeng H, Sun M, Hua Y, Cai Z. Is fibrin sealant effective and safe in total knee arthroplasty? A meta-analysis of randomized trials. J Orthop Surg Res. 2014;9:36.
International Journal of Clinical Transfusion Medicine

\section{Publish your work in this journal}

International Journal of Clinical Transfusion Medicine is an international, peer-reviewed, open access, online journal publishing clinicalexperimental, policy-making and evidence-based practices of all topics pertaining to clinical transfusion medicine. Original research, short reports, reviews, case reports and commentaries are invited.

\section{Dovepress}

The manuscript management system is completely online and includes a very quick and fair peer-review system, which is all easy to use. Visit http://www.dovepress.com/testimonials.php to read real quotes from published authors. 